\title{
Developing a Novel Contactless Sensor for Helicopter Rotor State Measurements
}

\author{
Potito Cordisco ${ }^{1}$, Rui Liü ${ }^{2}$, Matteo Redaelli ${ }^{3}$, Luca Riviello ${ }^{3}$, Alberto Rolando ${ }^{4}$, Federico Rossi ${ }^{4}$, \\ Lorenzo Trainelli ${ }^{4}$, Edoardo Vigoni ${ }^{1}$, Emanuele Zappa ${ }^{2}$ \\ ${ }^{1}$ Vicoter, Via Stoppani, Calolziocorte, 23801 Italy \\ 2 Politecnico di Milano, Department of Mechanical Engineering, Via G. La Masa 1, 20156 Milano, Italy \\ ${ }^{3}$ Finmeccanica Helicopter Division, Via G. Agusta 520, Cascina Costa di Samarate, Varese, Italy \\ ${ }^{4}$ Politecnico di Milano, Department of Aerospace Science and Engineering, Via G. La Masa 34, 20156 \\ Milano, Italy \\ Iorenzo.trainelli@polimi.it
}

\begin{abstract}
The present contribution concerns the development of an innovative measurement system for rotorcraft applications. This system aims at the real-time acquisition of the motion of a rotor blade in flight, for applications in emitted noise prediction and monitoring, and in rotor state feedback control augmentation. A structured approach to the system design, implementation and testing has been pursued starting from a survey of applicable technologies. Contactless solutions were targeted, in view of maximum compatibility with a wide class of vehicles. A first development phase saw the selection of three concepts, all conceived to be mounted on the rotor head and pointing the blade root area, based either on 2-D laser transducers or on vision-based sensors. These were implemented in full scale and laboratory tested to choose the most promising for definitive development. The final solution, a stereoscopic vision-based measurement system, was brought to maturity through further development and laboratory testing, up to fully integration on board a prototype helicopter for ground and flight testing. We detail the various stages in this process, motivating the choices made and illustrating the results in terms of measurement accuracy.
\end{abstract}

Key words: Helicopter blade motion, flapping sensor, blade angle measurement, rotor state feedback, contactless sensing.

\section{Introduction}

The ability to acquire on board, in real-time, the motion of a helicopter rotor blade is gaining increasing importance, in view of an improvement of pilot-vehicle capabilities and a widening of the spectrum of rotorcraft flight procedures and operational tasks. In fact, on one hand, rotary-wing vehicles are prone to possibly significant dynamic behaviors impacting on comfort as well as pilot workload, while on the other hand their operations are often limited by the admissible levels of external noise emitted, which inhibits flying terminal procedures over densely inhabited areas. By measuring blade motion on the fly, this information could be processed in order to derive specific quantities used in the estimation of rotor (and hence vehicle) dynamics, with multiple applications, such as noise estimation, vehicle closed-loop control laws, vehicle monitoring, or parameter identification.

In spite of the potential advantages, to date no operational rotorcraft is permanently fitted with equipment devoted to the real-time acquisition of blade motion, of either the main or tail rotor.

Temporary provisions are sometimes employed by rotorcraft manufacturers in the development of new rotorcraft models or versions, as elements of the installed Flight Test Instrumentation. Examples of these kind of sensor systems are given in [1,2]. The former is based on a combination of accelerometer sensors and an observation algorithm for the retrieval of blade motion and load data, while the latter relies on direct mechanical probing through LVDT-fitted rods. These experimental devices are subject to different requirements than production equipment, reflected in 
specialized setups with low degrees of integration and portability, and relatively low levels of reliability and endurance.

The present contribution synthetically illustrates a structured approach to the design, implementation and testing of a new rotor state measurement system for rotorcraft applications, conceived as potentially integratable on board current and future production helicopters. This effort has been recently carried out in the framework of a Clean Sky collaborative project in which the novel sensor system plays a fundamental role, enabling the setup of an innovative integrated system for rotorcraft inflight noise monitoring.

\section{The MANOEUVRES Project}

The Clean Sky MANOEUVRES (Manoeuvring Noise Evaluation Using Validated Rotor State Estimation Systems) project is focused on novel solutions in support to the implementation of low acoustic impact rotorcraft terminal procedures [3]. In this 32-month program involving two universities, Politecnico di Milano and Università Roma Tre, and two companies, Vicoter and Logic, with the close cooperation of Finmeccanica Helicopter Division (FHD), an articulated agenda of innovative research activities has been pursued in the attempt to demonstrate the feasibility of an approach to on board, real-time noise monitoring through an estimation of the running acoustic emission based on rotor blade measurements.

To this end, an algorithm providing an estimation of a suitable 'noise index' feeds a new instrument, the PAl (Pilot Acoustic Indicator) [4], for graphical presentation in the cockpit. This algorithm retrieves interpolated SPL (Sound Pressure Level) distributions within a database of pre-calculated steady-state acoustic predictions. The input for this process is given by the current values of three parameters, to which noise emission is strongly related: the helicopter advance ratio, the main rotor thrust coefficient, and the main rotor tippath-plane (TPP) angle of attack, or TPP-AOA [5]. The on-board measurement of these parameters poses some difficulties. In particular, the thrust coefficient and the TPPAOA are only roughly estimated on the basis of simplified models of the vehicle fed by data extracted from the helicopter avionics (airspeed, altitude, etc.).

However, if a rotor state measurement system is present, the current blade motion (and in particular the cyclic flappings) can be evaluated, leading to a direct estimation of the TPP orientation with respect to the rotor fuselage. This, coupled with an estimation of the fuselage angle of attack and sideslip, may lead to the achievement of the TPP-AOA. Again, this may be difficult, especially in the case of production helicopters, which are not endowed with appropriate sensors for fuselage aerodynamic angles, such as swiveling air data booms. Therefore, for the MANOEUVRES approach, a solution may be found in applying the observation methodology described in [6], by which thrust coefficient and TPP-AOA can be conveniently estimated exploiting the rotor state measurements.

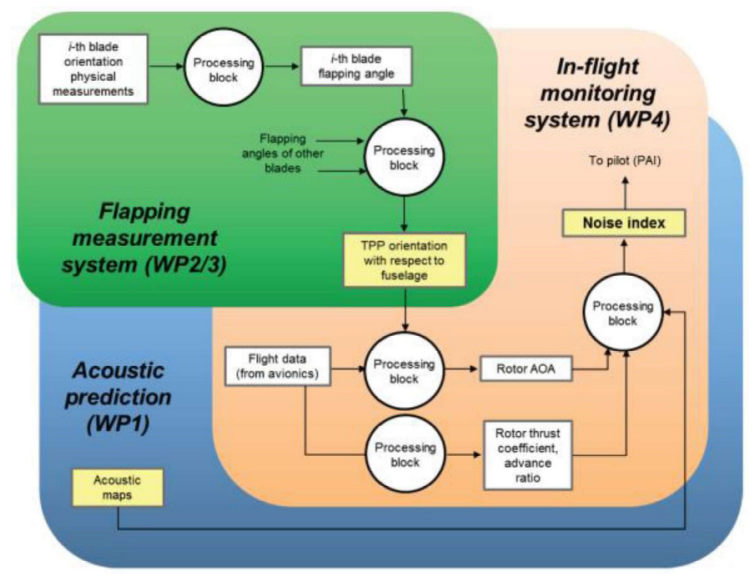

Fig. 1. Schematics of the noise index estimation process within the MANOEUVRES workflow.

Figure 1 depicts the general process in which acoustic predictions produced in the MANOEUVRES Work Package 1 contribute, together with the rotor state measurements provided by the sensor system developed in Work Packages 2 and 3, to the input for the PAI algorithm, developed in Work Package 4.

In addition to this process, in the technical Work Packages (WPs) of the MANOEUVRES project, other activities have been pursued. Indeed, in WP4, the full implementation of the PAI has been carried out, with the realization fo a standalone prototype that has been integrated within a FHD research flight simulator for a thorough trial campaign with professional test pilots.

In an effort to assess the capability to accurately predict the noise footprint of a maneuvering rotorcraft, in WP1 two variants of a quasi-steady computational approach have been compared to fully unsteady calculations in relation to typical and low-noise terminal trajectories $[7,8]$. The highly accurate, but inevitably burdensome, unsteady aeroacoustic solver, coupled with a sophisticated propagation model, has been used to correlate predictions with actual flight test data. Also, the sensitivity of the predictions with respect to 
perturbations in the nominal trajectory have been studied.

In WP2 and 3, the availability of a rotor state measurement system on board was seen as a motivation to investigate an innovative approach to Rotor State Feedback (RSF) attitude control augmentation. Structured controllers have been applied to a reduced, linearized rotor/fuselage model $\left(2^{\text {nd }}\right.$ order in hover and $5^{\text {th }}$ order in forward flight up to intermediate airspeeds), taking into account a realistic model of the rotor state measurement system, including related values of the sampling frequency and time delay. This activity demonstrated significant potential benefits in pilot/vehicle performance, easing pilot workload and enhancing rotorcraft stability $[9,10]$.

A detailed overview of the results obtained in WP1 and WP4 at 24 months from the project inception is offered in [11]. Here, we delve on the process accomplished in WP2 and WP3, concerning the full-scale development of a novel contactless measurement system mounted on the main rotor head, from preliminary studies to the final integration on board a prototype helicopter for ground and flight testing.

\section{Design Requirements and Technology Survey}

For the development of a new rotor sensor system capable of accurate measurements of coupled lead-lag, flap and pitch blade motions, contactless technologies were considered, in an effort to improve system durability and exploit a higher intrinsic flexibility of application. In fact, we targeted a product-oriented prototypal application showing the potential to be fitted on main and tail rotors mounted on operational rotorcraft of different size and configuration.

Appropriate requests, constraints and limitations for the rotor state measurement system to be developed were defined, in view of such an ambitious goal, before carrying out a thorough technology survey. Among these requirements, we identified functional characteristics, physical characteristics, and environmental characteristics.

Functional characteristics involve metrological performance, needed to permit the use of the system in noise prediction, as well as in other promising applications. The analysis led to identify the values shown in Table 1 for measurement bandwidth, accuracy, and range.

Tab. 1: Measurement system performance requirements

$$
\begin{array}{l|l}
\text { Bandwidth } & 0-10 \mathrm{~Hz} \text { (minimum) }
\end{array}
$$

\begin{tabular}{|c|c|}
\hline & $0-25 \mathrm{~Hz}$ (desired) \\
\hline Accuracy & $\begin{array}{c}0.5 \mathrm{deg} \text { (minimum) } \\
0.1 \mathrm{deg} \text { (required) }\end{array}$ \\
\hline \multirow{2}{*}{ Range } & $\begin{array}{c}\text { lead-lag: }(-13.5,10.3) \mathrm{deg} \\
\text { flap: }(-6.0,18.0) \mathrm{deg} \\
\text { pitch: }(-22.0,20.0) \mathrm{deg}\end{array}$ \\
\hline
\end{tabular}

Also, the capability to operate satisfactorily on board a helicopter was considered by identifying the need to achieve the measurement while subjected to the loads induced by the in-service accelerations and vibration levels.

Physical characteristics include elements such as weight, geometry, power consumption, and installation requirements, considering both options of installation on the main rotor or on the fuselage airframe. For environmental characteristics, we considered a maximum altitude up to $6,100 \mathrm{ft}$, and a temperature range from $-40^{\circ} \mathrm{C}$ to the maximum found on the relevant helicopter area. Numerous other requirements, complying to the applicable requests found in the MIL-STD-704E and RTCA/D0160D standards were also included.

Based on this analysis, we carried out an assessment of candidate technologies, considering the sensor types listed in Table 2.

Tab. 2: Types of sensors considered in the preliminary studies

\begin{tabular}{|c|c|c|}
\hline N. & Technology & Installation \\
\hline 1 & Capacitive & On rotor \\
\hline 2 & Ultrasonic & On rotor \\
\hline 3 & Eddy current & On rotor \\
\hline 4 & Hall effect & On rotor \\
\hline 5 & Magneto-inductive & On rotor \\
\hline 6 & $\begin{array}{c}\text { 1-D and 2-D laser } \\
\text { triangulation }\end{array}$ & $\begin{array}{c}\text { On rotor } \\
\text { On fuselage }\end{array}$ \\
\hline 7 & $\begin{array}{c}\text { Time-of-flight laser } \\
\text { On rotor } \\
\text { On fuselage }\end{array}$ \\
\hline 8 & Vision systems & $\begin{array}{c}\text { On rotor } \\
\text { On fuselage }\end{array}$ \\
\hline
\end{tabular}

Initially, all sensor types were considered for possible installation on the rotor, while only types 6-8 were deemed to be suitable to a fuselage-mounted solution. This is justified by the limitations in range characteristics of types $1-5$, which pose serious problems in targeting the main rotor blade from a location on the fuselage on a typical helicopter. However, a 
further step in the study led to reduce the number of candidates to only types 6 and 8 , in view of a reduced risk in obtaining poor measurement characteristics.

Indeed, types 1-5 may suffer of a marked sensitivity to possibly wide variations in environmental conditions, which is typical of flight applications. For example, capacitive sensor measurements are influenced by dirt, moisture, water and other perturbations to the dielectric media. Ultrasonic sensors can be fairly sensitive too to various environmental variations, including air turbulence. In some cases, these problems add to short measuring ranges and inherent difficulties in measuring a fully tri-dimensional, large amplitude motion, such as with eddy current, Hall effect and magneto-inductive transducers. In these cases, the potentially wide amplitude of the motion to be captured struggles with the need of an accurate, constant alignment with the target. Finally, time-of-flight laser systems were discarded for their relatively low sampling frequency.

This preliminary assessment allowed to choose types 6 (1-D and 2-D laser triangulation) and 8 (vision systems) as the most promising for candidate rotor state measurement system concepts.

\section{Preliminary Concept Selection}

Given the potential compliance of laser triangulation-based systems and vision-based systems to the preliminary requirements discussed above, the next phase requested to conceive three competing implementations and to test them on appropriate test benches. Based on measured performance, a final selection was eventually accomplished to determine the definitive rotor state measurement system solution, to be integrated on board a AW139, a 15-seat, 7-ton class, twinengine helicopter.

The three candidates were sorted out of a set of nine possible solutions, listed in Table 3.

Tab. 3: Possible rotor state measurement system solutions considered in the preliminary studies

\begin{tabular}{|c|c|c|}
\hline N. & Sensor type & $\begin{array}{c}\text { Sensor position } \\
\text { and target }\end{array}$ \\
\hline F1 & Single point laser & $\begin{array}{c}\text { Fuselage to } \\
\text { blade }\end{array}$ \\
\hline F2 & 2-D laser & $\begin{array}{c}\text { Fuselage to } \\
\text { blade }\end{array}$ \\
\hline F3 & $\begin{array}{c}\text { Vision-based single } \\
\text { camera }\end{array}$ & $\begin{array}{c}\text { Fuselage to } \\
\text { blade }\end{array}$ \\
\hline
\end{tabular}

\begin{tabular}{|c|c|c|}
\hline R1 & Single point laser & $\begin{array}{c}\text { Hub top to } \\
\text { blade root }\end{array}$ \\
\hline R2 & 2-D laser & $\begin{array}{c}\text { Hub top to } \\
\text { blade root }\end{array}$ \\
\hline R3 & $\begin{array}{c}\text { Vision-based single } \\
\text { camera }\end{array}$ & $\begin{array}{c}\text { Hub top to } \\
\text { blade root }\end{array}$ \\
\hline R4 & $\begin{array}{c}\text { Vision-based } \\
\text { stereoscopy }\end{array}$ & $\begin{array}{l}\text { Hub top to } \\
\text { blade root }\end{array}$ \\
\hline R5 & $\begin{array}{c}\text { Vision-based single } \\
\text { camera }\end{array}$ & $\begin{array}{l}\text { Hub top to } \\
\text { blade tip }\end{array}$ \\
\hline R6 & $\begin{array}{c}\text { Vision-based single } \\
\text { camera }\end{array}$ & $\begin{array}{c}\text { Hub side to } \\
\text { blade root }\end{array}$ \\
\hline
\end{tabular}

Six rotor-mounted $(\mathrm{R} x)$ and three fuselagemounted $(F x)$ solutions were considered. An important element in this regard is the fundamental difference in the ability to capture harmonic components in the motion of the target. In fact, for all rotor-mounted solutions, where the target (a part of the blade) virtually stays in the field of view of the transducer at all times, a single sensor with an adequate sampling rate allows to acquire all frequencies of interest. On the contrary, the frequency content sensed by sensors employed in fuselage-mounted solutions is strictly a function of their number, given that they can only acquire at each blade passage.

This played an important role in the choice of the three candidates, which were evaluated by applying the Analytic Hierarchy Process (AHP) [12] by defining a number of ranking parameters grouped into the following classes: (a) weight, cost and helicopter requirements; (b) technical challenge; (c) technical capability; (d) road to commercial exploitation. In this way, we contemplated measuring performance along with numerous characteristics that must be taken into account when pointing to a potentially airworthy and product-oriented industrial application. The resulting overall ranking for the concepts is shown in Figure 2.

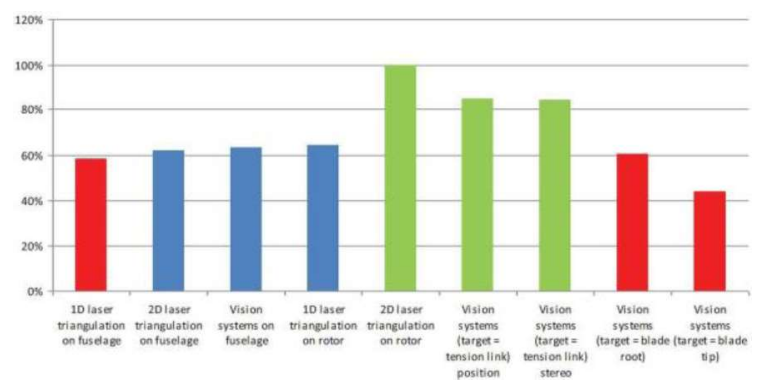

Fig. 2. AHP ranking for the possible rotor state measurement system solutions (from left to right: F1 to F3, followed by R1 to R6). 
The three higher-ranked concepts are all rotormounted solutions with the transducers installed atop the hub and pointing to some part of the blade root. The winner emerged as solution R2 (2-D laser triangulation), followed by solutions R3 (vision-based single camera) and R4 (vision-based stereoscopy), scoring the same mark.

\section{Preliminary Development and Testing}

For each of the three surviving solutions, a prototypal, full-scale implementation was assembled and a thorough test campaign was carried out in order to characterize transducer functionality and measurement performance.

Aiming to assess these characteristics in representative laboratory conditions, we considered three types of experiments:

- Type I tests: the systems were fitted to a shaker and, during the acquisition, subjected to realistic tri-axial vibration levels replicating actual flight data measured on board a AW139.

- Type II tests: the systems were installed on two different non-rotating rigs for accuracy assessment.

- Type III tests: the systems were installed on a rotating rig replicating the actual main rotor speed of a AW139, stressing the equipment with realistic centrifugal loads during the acquisition.

For Type II tests, a pure flapping rig was built at the Politecnico di Milano laboratories (Figure 3). This was achieved assembling speciallyproduced elements with real helicopter components, to faithfully reproduce the geometry of the installed system. Static flap angles, as well as harmonic flap motion, can be imposed to the blade retention elements.

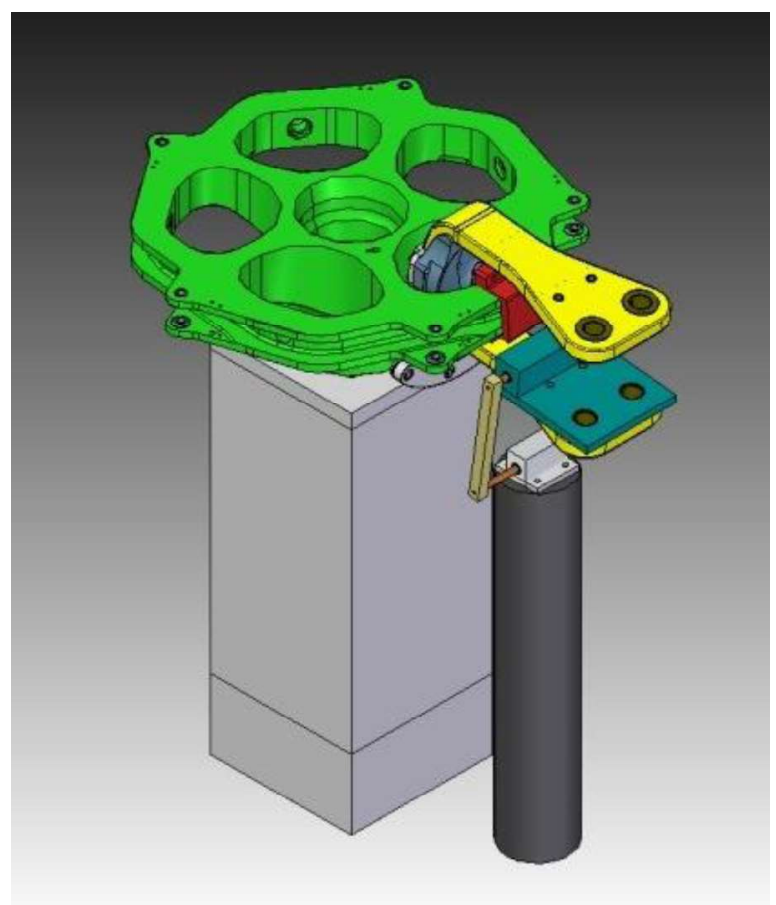

Fig. 3. Pure flapping rig employed for Type II tests.

A second, highly representative rig was also employed in Type II tests: the AW139 endurance testbed available at the FHD premises in Cascina Costa. This is a highly complex device used for main rotor component testing, which allows to impose fully coupled lead-lag/flap/pitch blade motions and simulates the effects of the centrifugal pull on the blade. In some trials, actual blade motion time histories retrieved from AW139 flight test data were reproduced.

Also in Type III tests a special attention was put in achieving a highly representative operating condition. In this case, we employed the A109MKII ironbird available at the Politecnico di Milano laboratories (Figure 4). This test bench is based on a Agusta A109MKII helicopter fuselage, devoid of the tail section, complete with the transmission gearbox and mast. The engines have been replaced by electric motors, the hub assembly is simplified, and the rotor head is fitted with two aerodynamic brakes in place of the blades. With this equipment, real centripetal accelerations and representative vibrations resulting from the gearbox can be reproduced. 


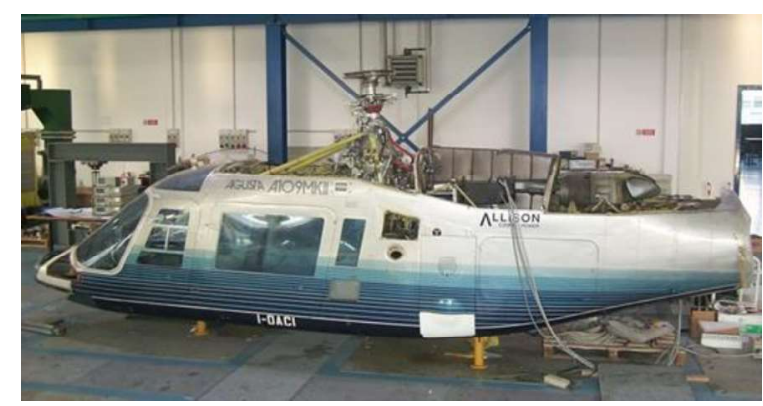

Fig. 4. The A109MKI ironbird employed for Type III tests.

All three candidate systems passed Type I and Type III tests, showing continuous operations, with acquisition and data transfer unaffected by sustained vibration and acceleration levels.

In Type II testing, a rich test matrix was put to trial, with numerous single axis and coupled combinations of static and harmonic leadlag/flap/pitch rotations. During these tests, some differences were detected between the three candidate systems concerning accuracy. Examples are given in Figures 5 and 6, where the errors on the measure of the mean value and the amplitude, respectively, are given in the case of a sinusoidal 1xrev (i.e. containing only the first harmonic) pure flapping time history. As apparent, while all three candidate systems exhibit errors below 1 deg about all axes, the 2D laser solution is characterized by greater inaccuracies. Similar results are obtained when looking at pure lead-lag motions, pure pitch motions, as well as for coupled leadlag/flap/pitch motions. A case of actual blade motion time histories retrieved from AW139 flight test data is presented in Figure 7 for the error on the mean value. In this specific case, the errors on the 1 xrev and $2 x r e v$ amplitudes showed similar trends, with maximum values of $0.54 \mathrm{deg}(\mathrm{R} 2)$ and $0.03 \mathrm{deg}$ (R2) in lead-lag, of $0.35 \mathrm{deg}$ (R3) and $0.07 \mathrm{deg}$ (R3) in flap, and of $0.21 \mathrm{deg}(\mathrm{R} 3)$ and $0.20 \mathrm{deg}(\mathrm{R} 3)$ in pitch.

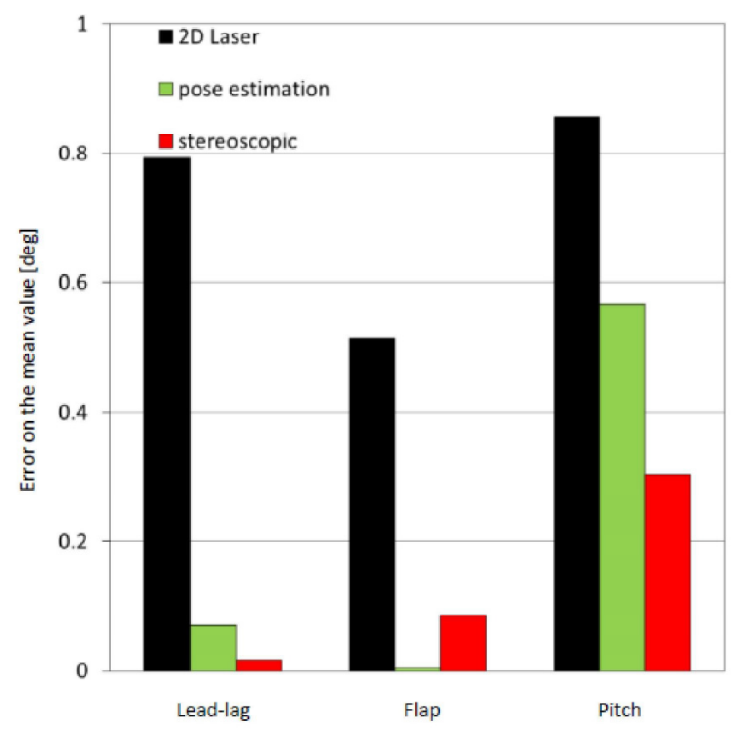

Fig. 5. Error on the mean values for a pure flapping harmonic 1 xrev time history.

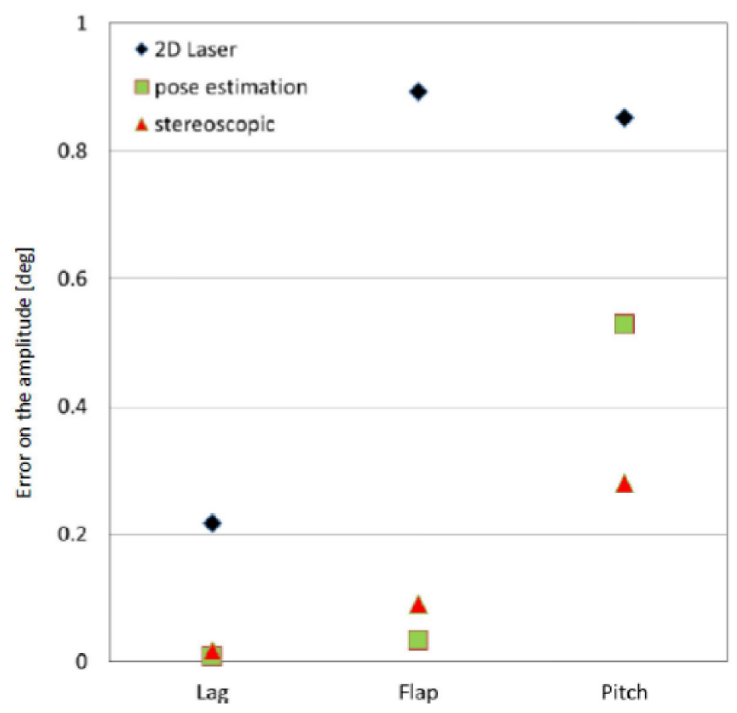

Fig. 6. Error on the amplitude for a pure flapping harmonic 1 xrev time history. 


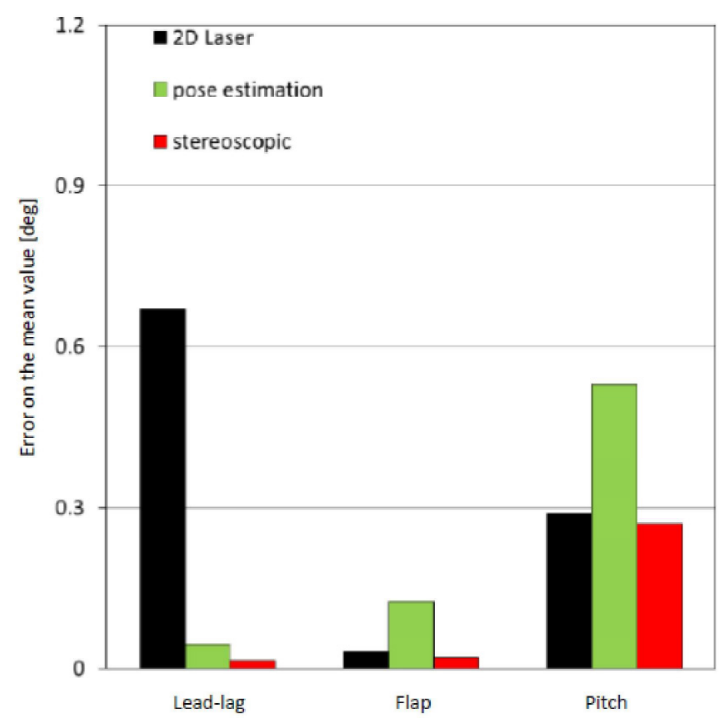

Fig. 7. Error on the mean value for a coupled leadlag/flap/pitch time history corresponding to flight test data.

Globally, only the vision-based systems R3 and R4 allowed measurements of the mean values and first harmonic components of the three angles in compliance with the mandatory accuracy of $0.5 \mathrm{deg}$. The highest accuracy is achieved by the stereoscopic vision-based system R4, which achieves the desired accuracy requirement of 0.1 deg when considering the first harmonic.

These results compare favorably to those recently published in [13], where the accuracy of a magnet-based tail-rotor measurement system tested in simplified conditions that did not involve fully coupled blade motions, was achieved as $1.0 \mathrm{deg}$ in lead-lag, $0.3 \mathrm{deg}$ in flap, and over $1.0 \mathrm{deg}$ in pitch.

\section{Final Development and Testing}

Based on the demonstrated results, the stereoscopic vision-based system concept was eventually selected to be brought to maturity in the final phase of the project. This process involved the improvement of the concept to obtain a definitive prototype, through further hardware and software development and testing, and the final integration on board an actual AW139 helicopter for ground and flight demonstration and testing.

The additional testing was performed on the definitive system fitted to the AW139 'beanie', a hat-shaped component placed on the top of the main rotor mast, above the hub. Figure 8 shows the installation of the system. The main elements of the rotor state measurement system are the two cameras and a LED lighting device to illuminate the target on the blade root.
The necessary balancing masses are also seen. The control unit with its wirings to collect power and transfer data to and fro the airframe systems is housed inside the central cylinder.

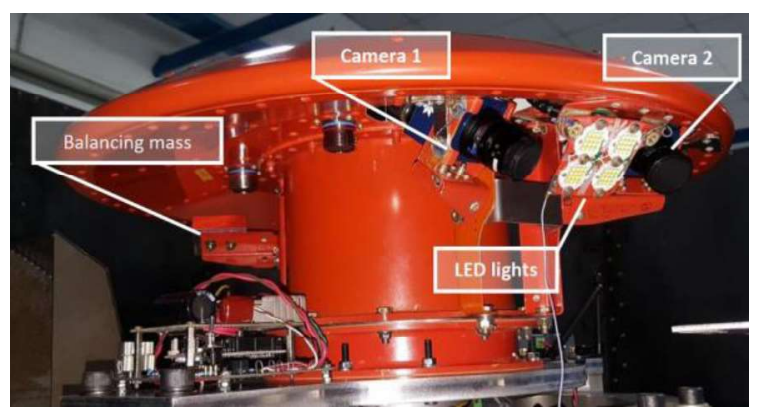

Fig. 8. AW139 experimental beanie instrumented with the final rotor state measurement system.

We carried out numerical and experimental structural verifications to clear the design from possible stability problems, and to insure that sufficient structural strength was guaranteed for the elements supporting the sensor system, to prevent potential measurement errors. Subsequently, the final integrated system was tested at Politecnico di Milano laboratories for definitive validation before being installed on board. We considered again three types of test, conceived to assess both safety and performance characteristics:

- Type I tests: the integrated system was fitted to a massive shaker and, during the acquisition, subjected to realistic triaxial vibration levels replicating actual flight data measured on board a AW139.

- $\quad$ Type II tests: the integrated system was installed on a non-rotating rig for accuracy assessment.

- Type III tests: the integrated system was installed on the A109MKII irondbird for centrifugal load testing during the acquisition, as well as for sunlight sensitivity assessment.

In Type I and Type III tests, sustained conditions up to 5 minutes were experienced, without the occurrence of any structural or functional problem. In Type II testing a novel bench was rigged using a 7-degree-of-freedom robotic arm available at the laboratories of the Politecnico di Milano. In this way, arbitrary static positions and motions to the target, fitted to the end-effector, can be imposed, spanning the full envelope of interest. This trials allowed to refine the acquisition and post-processing algorithms and confirmed the accuracy levels obtained in the preliminary test campaign with the 
candidate systems. Furthermore, we studied the integrated system sensitivity to sunlight by placing a calibrated light in multiple positions during the rotation, to check its ability in collecting measurements while illuminated by the sun during flight operations. Due to the convenient placement of the sensors below the beanie rim, and of the relatively high sampling frequency, currently set at 7 measurements per rotor revolution, a low influence of sunlight on global measurements was observed.

Following these extensive laboratory trials, the integrated system achieved the necessary clearance for installation on an instrumented AW139 prototype. A power supply unit and a stand-alone data acquisition equipment have been designed and implemented, fully compliant with the prototype helicopter configuration. Furthermore, data acquired from the MANOEUVRES rotor state measurement system are also conveyed to the helicopter Flight Test Instrumentation (FTI) system for onboard storage on mass memories.

Ground tests and flight tests, ongoing at the moment of writing, aim at showing the integrated rotor state measurement system functionality in real conditions. Also, metrological performance will be assessed, in comparison to an independent, contact-based measurement system that will be concurrently installed on board [2].

\section{Concluding Remarks}

A novel, vision-based system for the real-time measurement of the motion of a helicopter rotor blade has been designed, developed, and tested within the framework of the Clean Sky GRC5 MANOEUVRES project, in view of noise monitoring and advanced vehicle control applications. The system is currently undergoing the final demonstration trials which involve ground and flight tests on board a AW139 instrumented prototype.

The initial requirements for the system involved metrological performance and airworthiness items, as well as considerations related to a possible product-oriented application, apt to be fitted on current and future rotorcraft models. A structured path was followed in the system development, involving a technology survey, the conception of nine possible architectural solutions, the selection of the three most promising candidates, their full-scale implementation and testing, the final choice of the definitive solution, and its final implementation, testing, and integration on board an actual helicopter.
As a result, a stereoscopic camera system mounted above the rotor hub and pointing towards a target located in the blade root area was devised. Future communications will detail the results of the final demonstration in flight for this promising system which displayed full compliance to applicable requests, constraints and limitations to date.

\section{Acknowledgements}

The research leading to these results has received funding from Project MANOEUVRES, financed by the Clean Sky Joint Undertaking Programme under Grant Agreement N. 620068.

\section{References}

[1] McKillip R., A Novel Instrumentation System for Measurement of Helicopter Rotor Motions and Loads Data, American Helicopter Society $58^{\text {th }}$ Annual Forum, Montreal, Canada, June 11-13, 2002.

[2] Colombo A., Locatelli A., Measuring Blade Angular Motions: A Kinematical Approach, $30^{\text {th }}$ European Rotorcraft Forum ERF 2004, Marseilles, France, September 14-16, 2004.

[3] Trainelli L., Cordisco P., Gennaretti M., Grassetti R., Lovera M., Redaelli M., Rolando A., Zappa E., Innovative RotorState Measurements Enabling Helicopter InFlight Noise Monitoring and Enhanced Attitude Control, American Helicopter Society $72^{\text {nd }}$ Annual Forum, West Palm Beach, FL, May 17-19, 2016.

[4] Rolando A., Rossi F., Riboldi C. E. D., Trainelli L., Grassetti R., Leonello D., Redaelli M., The Pilot Acoustic Indicator: A Novel Cockpit Instrument for the Greener Helicopter Pilot, $41^{\text {st }}$ European Rotorcraft Forum ERF 2015, Munich, Germany, September 1-4, 2015.

[5] Gennaretti M., Serafini J., Bernardini G., Castorrini A., De Matteis G., Avanzini G., Numerical Characterization of Helicopter Noise Hemispheres, Aerospace Science and Technology 52, 18-28 (2016) doi: 10.1016/j.ast.2016.02.013

[6] Trainelli L., Riboldi C. E. D., Bucari M., Observing the Angle of Attack of the TipPath Plane from Rotor Blade Measurements, $41^{\text {st }}$ European Rotorcraft Forum ERF 2015, Munich, Germany, September 1-4, 2015.

[7] Bernardini G., Anobile A., Serafini J., Hartjes S., Gennaretti M., Methodologies for Helicopter Noise Footprint Prediction in Manoeuvring Flights, $22^{\text {nd }}$ International Conference on Sound and Vibration Proceedings, Firenze, Italy, July 12-16, 2015.

[8] Gennaretti M., Bernardini G., Anobile A., Serafini J., Trainelli L., Rolando A., 
Scandroglio A., Riviello L., Acoustic Prediction of Helicopter Unsteady

Manoeuvres, $41^{\text {st }}$ European Rotorcraft

Forum ERF 2015 Proceedings, Munich,

Germany, September 1-4, 2015.

[9] Panza S., Lovera M., Rotor State Feedback in the Design of Rotorcraft Attitude Control Laws, Advances in Aerospace Guidance,

Navigation and Control, edited by J.

Bordeneuve-Guibè, A. Drouin and C. Roos, Springer International Publishing,

Switzerland, 2015, pp. 205-225; ISBN 9783-319-17517-1.

[10] Panza S., Bergamasco M., Viganò L., Lovera M., Rotor State Feedback in Rotorcraft Attitude Control, $41^{\text {st }}$ European Rotorcraft Forum ERF 2015, Munich, Germany, September 1-4, 2015.

[11] Trainelli L., Gennaretti M., Bernardini G., Rolando A., Riboldi C. E. D., Redaelli M., Riviello L., Innovative Helicopter In-Flight Noise Monitoring Enabled by Rotor State Measurements, Noise Mapping (under review).

[12] Saaty Th. L., Decision Making for Leaders -The Analytic Hierarchy Process for Decisions in a Complex World, RWS Publishing, Pittsburgh, PA, 1990; ISBN 09620317-8-X.

[13] Schank T. C., Schulte K. J., Smart Position Sensor for Articulated Rotors, American Helicopter Society 71st Annual Forum, Virginia Beach, VA, May 5-7, 2015. 